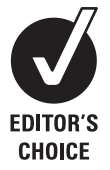

See Editorial Commentary, p 586

${ }^{1}$ Department of Neurology, University of Cologne, Cologne, Germany; ${ }^{2}$ Institute of Neuroscience and Medicine (IN3M), Research Centre Jülich, Jülich, Germany

Correspondence to: Dr D A Nowak,

Neurochirurgische und

Neurologische Fachklinik, Klinik

Kipfenberg, Kindinger Strasse

13. D-85110 Kipfenberg:

ca@neurologie-kipfenberg.de

Received 18 August 2008

Revised 12 October 2008

Accepted 23 October 2008

Published Online First

14 November 2008

\title{
Electrical somatosensory stimulation improves movement kinematics of the affected hand following stroke
}

\author{
I B M Koesler, ${ }^{1}$ M Dafotakis, ${ }^{2}$ M Ameli, ${ }^{1}$ G R Fink, ${ }^{1,2}$ D A Nowak ${ }^{1,2}$
}

\begin{abstract}
Aim: The effect of electrical somatosensory stimulation on motor performance of the affected hand was investigated in 12 chronic subcortical stroke subjects.

Methods: Subjects performed index finger and hand tapping movements as well as reach-to-grasp movements with both the affected and unaffected hand prior to (baseline conditions) and following (1) $2 \mathrm{~h}$ of electrical somatosensory stimulation (trains of five pulses at $10 \mathrm{~Hz}$ with $1 \mathrm{~ms}$ duration delivered at $1 \mathrm{~Hz}$ with an intensity on average $60 \%$ above the individual somatosensory threshold) of the median nerve of the affected hand or (2) $2 \mathrm{~h}$ of idle time on separate occasions at least 1 week apart. The order of sessions was counterbalanced across subjects.
\end{abstract}

Results: Somatosensory stimulation of the median nerve of the affected hand, but not a period of idle time, enhanced the frequency of index finger and hand tapping movements and improved the kinematics of reach-tograsp movements performed with the affected hand, compared with baseline. Somatosensory stimulation did not impact on motor performance of the unaffected hand. Discussion: The data suggest that electrical somatosensory stimulation may improve motor function of the affected hand after stroke; however, further studies are needed to test if the implementation of somatosensory stimulation in rehabilitation of hand function also impacts on manual activities of daily life after stroke.

In healthy people, neural activity within the motor areas of the two hemispheres is functionally coupled and well balanced for unimanual hand movements. ${ }^{1-5}$ In particular, there is a shift of neural activity towards motor areas of the contralateral hemisphere for movements of one hand. ${ }^{5}$ This functional lateralisation of neural activity is probably related to interhemispheric inhibition between the motor areas of each hemisphere transferred via callosal connections. ${ }^{2}{ }^{3}$ The interhemispheric competition model predicts that the balance of excitability between the motor areas of both hemispheres is changed subsequent to a stroke with enhanced excitability of the motor cortex of the unaffected hemisphere and abnormally increased interhemispheric inhibition exerted upon the motor cortex of the affected hemisphere. ${ }^{67}$ Within the context of interhemispheric competition, upregulation of excitability within the motor network of the affected hemisphere may improve motor function of the contralateral, that is affected hand after stroke.

Electrical somatosensory stimulation (ESS) can be used to enhance neural excitability within contralateral motor cortical areas. $^{89}$ In stroke subjects, ESS alone $e^{10}$ or in combination with motor training ${ }^{12-14}$ has the potential to aid relearning of motor skills with the affected hand. The present study was designed to investigate the effects of a $2 \mathrm{~h}$ ESS protocol ${ }^{81012}$ applied to the median nerve of the affected hand, compared with a $2 \mathrm{~h}$ period of idle time, on simple tapping movements of the index finger and hand as well as reach-to-grasp movements performed with either hand in chronic subcortical stroke subjects. Detection of a relevant improvement of movement kinematics of the affected hand would lend further support to the concept of interhemispheric competition after stroke. Furthermore, enhancing our knowledge of the aspects of movement that are sensitive to ESS appears essential, given current efforts to implement peripheral and central nervous system stimulation techniques in stroke rehabilitation.

\section{SUBJECTS AND METHODS \\ Subjects}

Twelve subjects (two women, aged 50 to 78 years, mean age: 67 (SD 7) years) in the chronic phase ( $>6$ months) after a single ischaemic subcortical middle cerebral artery stroke participated. All subjects were right-handed according to a handedness questionnaire. ${ }^{15}$ Subjects met the following criteria: (1) presentation with mild to moderate motor and/or sensory deficits at the hand, (2) absence of relevant spasticity in the affected upper limb, (3) a score of $>24$ points on the Folstein's Mini Mental Status Examination, ${ }^{16}$ (4) absence of aphasia that would interfere with the examination, (5) ability to bisect a straight horizontal line within $5 \%$ of the mid point ${ }^{17}$ and unimpaired visual fields at both eyes as measured by finger perimetry, (6) negative screening for ideomotor apraxia, ${ }^{18}$ (7) absence of a relevant depression as suggested by a score of less than 18 points on the Beck Depression Inventory, ${ }^{19}(8)$ a first ischaemic subcortical lesion within the territory of the MCA verified by magnetic resonance imaging (T1-weighted, T2weighted and FLAIR images) and (9) ability to complete the experimental protocol with the affected and unaffected hand. Clinical details are summarised in table 1. All subjects suffered from mild to moderate impairment of fine motor control of the affected hand that equally impacted on the grasp, grip and pinch subscales of the Action Research Arm Test (ARAT), ${ }^{20}$ but less on the gross movement subscale. The study was approved by the Ethics Committee of the University of 
Table 1 Clinical details

\begin{tabular}{|c|c|c|c|c|c|c|c|c|c|c|c|c|}
\hline Patient & $\begin{array}{l}\text { Age } \\
\text { (years) }\end{array}$ & Gender & $\begin{array}{l}\text { Stroke } \\
\text { localisation }\end{array}$ & $\begin{array}{l}\text { Time from } \\
\text { stroke } \\
\text { (months) }\end{array}$ & $\begin{array}{l}\text { Affected } \\
\text { hand }\end{array}$ & $\begin{array}{l}\text { Hand } \\
\text { dominance }\end{array}$ & $\begin{array}{l}\text { MMS } \\
\text { Score }\end{array}$ & $\begin{array}{l}\text { NIHSS } \\
\text { Score }\end{array}$ & $\mathrm{mRS}$ & $\begin{array}{l}\text { ARAT } \\
\text { Score }\end{array}$ & BDI & $\begin{array}{l}\text { Sensibility } \\
\text { Impairment } \\
\text { Score }\end{array}$ \\
\hline 1 & 70 & Female & $B G$ & 17 & Left & Right & 30 & 1 & 1 & 54 & 7 & 8 \\
\hline 2 & 68 & Male & $B G$ & 22 & Left & Right & 30 & 3 & 1 & 51 & 5 & 11 \\
\hline 3 & 62 & Male & $\mathrm{CR}$ & 19 & Right & Right & 29 & 3 & 1 & 52 & 4 & 12 \\
\hline 4 & 66 & Male & BG, CR & 8 & Left & Right & 30 & 7 & 4 & 48 & 6 & 14 \\
\hline 5 & 72 & Male & $B G, I C$ & 10 & Left & Right & 30 & 6 & 2 & 53 & 6 & 18 \\
\hline 6 & 50 & Male & $\mathrm{CR}$ & 12 & Right & Right & 29 & 9 & 4 & 47 & 12 & 20 \\
\hline 7 & 67 & Male & $B G$ & 19 & Right & Right & 30 & 2 & 1 & 53 & 0 & 16 \\
\hline 8 & 66 & Male & $\mathrm{BG}, \mathrm{CR}$ & 12 & Right & Right & 30 & 4 & 1 & 51 & 8 & 12 \\
\hline 9 & 74 & Male & $\mathrm{BG}$ & 17 & Right & Right & 30 & 4 & 2 & 50 & 8 & 13 \\
\hline 10 & 78 & Male & $B G$ & 19 & Left & Right & 30 & 3 & 1 & 51 & 6 & 20 \\
\hline 11 & 68 & Male & IC & 17 & Left & Right & 29 & 4 & 4 & 51 & 9 & 18 \\
\hline 12 & 68 & Female & IC & 16 & Left & Right & 29 & 2 & 1 & 52 & 7 & 10 \\
\hline
\end{tabular}

The Sensibility Impairment Score was rated as detailed previously $\left(0=\right.$ normal; greater score indicates more significant impairment; maximum score: 35 points). ${ }^{21}$ ARAT, Action Research Arm Test; ${ }^{20}$ BDI, Beck Depression Inventory ${ }_{i}^{19}$ BG, basal ganglia; CR, corona radiata; IC, internal capsule; MMS, Mini Mental status; ${ }^{16}$ mRS, Modified Rankin Score, ${ }^{23}$ NIHSS, National Institute of Health Stroke Scale. ${ }^{22}$

Cologne, and written informed consent was obtained prior to participation.

\section{Experimental procedures}

Kinematic motion analysis of simple index finger and hand tapping movements at the metacarpophalangeal joint and wrist, respectively, as well as reach-to-grasp movements were studied at both hands (1) prior to (baseline conditions 1 and 2) and following (2) $2 \mathrm{~h}$ of electrical supra-threshold somatosensory stimulation of the median nerve of the affected hand (stimulation condition) and (iii) $2 \mathrm{~h}$ of idle time (control condition). The median nerve was stimulated at the wrist. Sessions were separated by 1 week to avoid any carryover effects after electrical median nerve stimulation. The order of sessions was pseudorandomly assigned to each subject and counterbalanced across subjects. Subjects were completely naïve to the experimental hypothesis and received standardised instructions. Tapping movements should be performed as fast as possible. Reach-to-grasp movements should be performed rapidly, but as accurately as possible.

\section{Kinematic motion analysis}

Subjects performed index-finger tapping, hand tapping and a reach-to-grasp task with each hand (total duration approximately $7 \mathrm{~min}$ ) (fig 1). The movement kinematics were recorded using an ultrasonic motion analyser as described previously in detail. $^{21}$

Index-finger tapping and hand tapping were performed as fast as possible. Movement amplitude was $2 \mathrm{~cm}$ in the index finger task and $4 \mathrm{~cm}$ in the hand tapping task as indicated by a mark (fig 1A,B). Three $5 \mathrm{~s}$ trials were performed with each hand. For each trial, a $3 \mathrm{~s}$ time interval was chosen for further analysis, which started $1 \mathrm{~s}$ after initiation of the trial. To quantify movement performance, the following parameters were obtained: ${ }^{21}(1)$ movement frequency $(\mathrm{Hz})$ and (2) peak movement amplitude $(\mathrm{mm})$. All parameters were averaged across all three trials for each participant. During the reach-to-grasp task, subjects placed the hand with thumb and index finger touching each other on a starting mark (fig 1C). Subjects reached for a wooden cube (length, hide and width: $4 \mathrm{~cm}$; mass: $50 \mathrm{~g}$ ), grasped it between the tips of the index finger and thumb, lifted it $10 \mathrm{~cm}$ above the table (as indicated by another mark) and held it for $3 \mathrm{~s}$ before placing it back on the table. Ten such reach-tograsp movements were performed by each subject with each hand. Reach-to-grasp movements should be performed rapidly but accurately. For each reach-to-grasp movement, the following parameters were obtained: ${ }^{21}$ (1) peak of vertical wrist position $(\mathrm{mm}),(2)$ peak of vertical wrist velocity $(\mathrm{mm} / \mathrm{s}),(3)$ movement time (ms) of the wrist, (4) peak grip aperture (mm) and (5) time of peak grasp aperture as a percentage of movement time. All parameters were averaged across all trials performed by each participant.

\section{Electrical somatosensory stimulation}

ESS was performed using a technique similar to that described in earlier studies ${ }^{810} 12$ using a conventional stimulator (Nicolet Viking select IV, Conshohocken, Pennsylvania). Electromyographic background activity was continuously monitored using silver-silver-chloride electrodes positioned in a belly-tendon technique on the skin overlying the abductor pollicis brevis muscle. Silver-silver-chloride surface electrodes were positioned to stimulate the median nerve at the wrist. The electromyographic signal was amplified, filtered $(50-2000 \mathrm{~Hz}$ ) and digitised at a sampling rate of $5000 \mathrm{~Hz}$. First, the minimum intensity of stimulation at which subjects reported paraesthesias in the median nerve territory (somatosensory threshold) was measured three times. Trains of electrical stimulation consisting of five pulses at $10 \mathrm{~Hz}$ (1 ms duration each) were delivered every second. Stimulus intensity was then increased until subjects reported strong paraesthesias in the absence of pain, while compound muscle potentials recorded from the abductor pollicis brevis muscle were below $100 \mu \mathrm{V}$.

During the stimulation condition, the stimulation protocol detailed above was administered at this intensity (on average $60 \%$ above the individual somatosensory threshold) over a $2 \mathrm{~h}$ period. During the period of idle time, electrodes were positioned as detailed above. After assessment of the somatosensory threshold, the stimulation intensity was slowly reduced below threshold and then stopped within the first $5 \mathrm{~s}$ of stimulation.

\section{Statistical analysis}

After verification of normal distribution and homogeneity of variance, repeated-measures ANOVAs were calculated for each kinematic parameter with the factors "condition" (levels: (1) baseline 1, (2) baseline 2, (3) after idle time and (4) median nerve stimulation) and "hand" (levels: (1) affected hand and (2) unaffected hand). Post-hoc pairwise comparisons between 

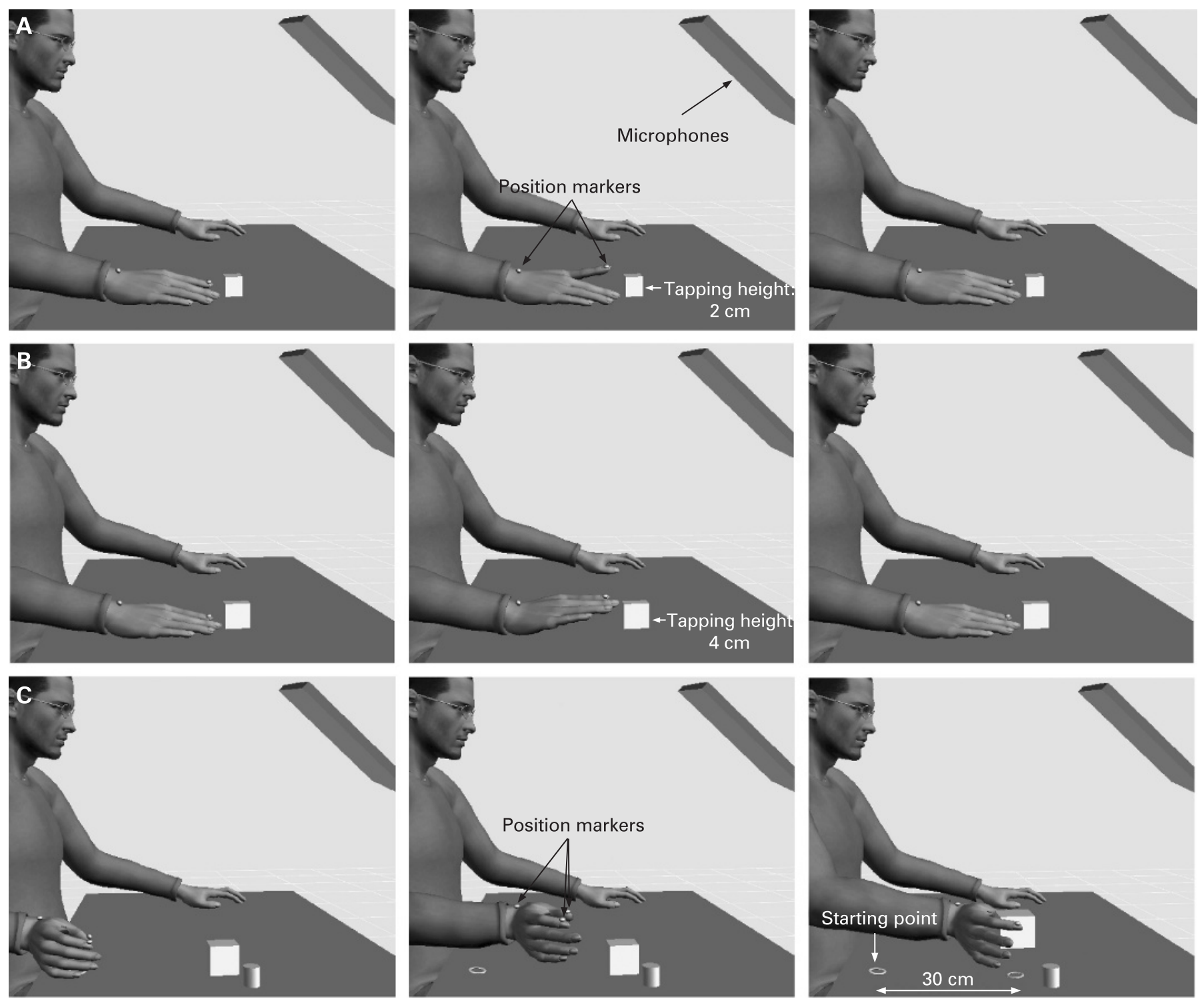

Figure 1 Recording of the $(A)$ index finger tapping, $(B)$ hand tapping and $(C)$ reach-to-grasp movements. Movement kinematics during each task was recorded using a three-dimensional motion analysis system based on ultrasound-emitting position markers. For the index finger tapping and hand tapping tasks, the position markers were fixed to the distal segments of the index finger and to the styloid process of the radius. For the reach-to-grasp task, position markers were fixed to the distal segments of the index finger and thumb, and to the styloid process of the radius.

conditions were performed using t tests. A p value of 0.05 was considered significant after Bonferroni correction for multiple comparisons.

\section{RESULTS}

All subjects performed the motor tasks according to the instructions and tolerated ESS well without any side effects.

\section{Index-finger and hand tapping}

The peak amplitudes of index-finger- and hand-tapping movements were not significantly influenced by "condition" or "hand." Likewise, the interaction between the factors did not exhibit a significant effect on peak amplitudes. Figure 2 illustrates the mean (SD) frequencies of index finger and hand tapping movements performed with each hand under each condition. It appears, however, as if ESS, but not a period of idle time, increased the frequency of both index finger and hand tapping movements performed with the affected hand.
The frequency of index-finger- and hand-tapping movements was significantly influenced by the factor "hand" (index finger tapping: $F_{1,11}=10.2 ; \quad p<0.01 ;$ hand tapping: $F_{1,11}=7.9$; $p<0.05$ ), suggesting reduced frequencies during performance with the affected hand. The factor "condition" did not significantly affect the frequency of index-finger- or handtapping movements. The interaction "condition" $x$ "hand" significantly affected the frequency of index finger tapping $\left(F_{1,11}=3.3 ; p<0.05\right)$, suggesting that median nerve stimulation, but not idle time, increased movement frequency of index finger tapping with the affected hand ( $p<0.01$ for each comparison). The interaction "condition" $\times$ "hand" exhibited no significant effect on the frequency of hand tapping movements $\left(F_{1,11}=3.1\right.$; $\mathrm{p}=0.1$.

\section{Reach-to-grasp movements}

Figure 3 summarises the mean (SD) values of peak wrist velocity, peak grasp aperture and the time of peak grasp 

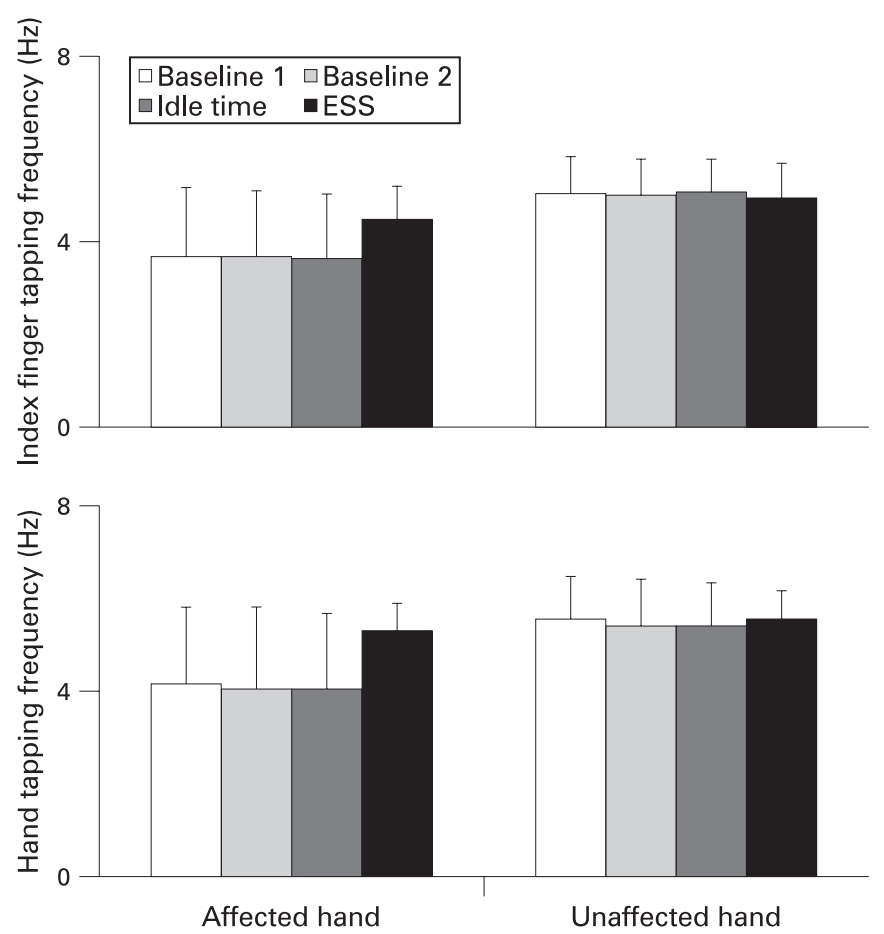

Figure 2 Average frequencies (+1SD) of index finger and hand tapping movements performed with the unaffected and affected hand prior to (baseline 1 and 2) and following a $2 \mathrm{~h}$ period of idle time or a $2 \mathrm{~h}$ period of electrical somatosensory stimulation. ESS, electrical somatosensory stimulation.

aperture as a percentage of movement time obtained from reach-to-grasp-movements performed with each hand. It seems as if ESS, but not a period of idle time, increased the peak velocity of the wrist during hand transport when performing reach-to-grasp movements with the affected hand. Peak grasp aperture of the affected hand, however, was not influenced by ESS. The time of peak grasp aperture as a percentage of movement time of wrist transport represents a measure of the temporal coupling between hand transport towards the cube and grasp formation. ESS shifted the time of peak grasp aperture towards the last third of movement time of the wrist when performing with the affected hand.

Peak wrist position was not significantly influenced by the factor "condition," "hand" or the interaction between both factors. Peak wrist velocity was significantly influenced by "hand" $\left(\mathrm{F}_{1,11}=16.4 ; \mathrm{p}<0.001\right)$, implying greater velocities for movements of the unaffected hand. A significant effect of the interaction "condition" $\times$ "hand" on peak wrist velocity $\left(\mathrm{F}_{1,11}=4.9 ; \mathrm{p}<0.01\right)$ indicates that ESS increased peak wrist velocity during reach-to-grasp movements performed with the affected hand. Similar, movement time of the wrist was significantly affected by "hand" $\left(\mathrm{F}_{1,11}=10.8 ; \mathrm{p}<0.01\right)$ and the interaction "condition" $\times$ "hand" $\left(F_{1,11}=2.9 ; p=0.05\right)$. In contrast, the factors "condition," "hand" or the interaction between both factors did not significantly impact on peak grasp aperture. The time of peak grasp aperture as a percentage of movement time was significantly affected by "hand" $\left(\mathrm{F}_{1,11}=8.3 ; \mathrm{p}=0.01\right)$ and "condition," suggesting that peak grasp aperture occurred later for movements of the unaffected hand and after ESS. A significant interaction "condition" $\times$ "hand" $\left(\mathrm{F}_{1,11}=3.8 ; \mathrm{p}<0.05\right)$ implies that for movements of the affected hand, the time of peak grasp aperture occurred later within the course of wrist transport after ESS.

\section{DISCUSSION}

The present study tested the effects of electrical somatosensory stimulation of the median nerve on the performance of dextrous movements in patients suffering from mild to moderate sensory-motor impairment of the hand without relevant spasticity in the chronic stage following a single subcortical stroke. We found that $2 \mathrm{~h}$ of ESS applied to the median nerve of the affected hand, but not $2 \mathrm{~h}$ of idle time, improved the kinematics of simple index finger- and hand-tapping movements as well as reach-to-grasp movements performed with the affected hand. In contrast, ESS did not impact on dexterity of the unaffected hand. Stroke subjects were completely naïve regarding the hypothesis of the study, and carryover or order effects of the stimulation sessions were avoided. Peripheral nerve stimulation was well tolerated by all subjects. In stroke subjects, ESS of a peripheral hand nerve, alone ${ }^{10} 11$ or applied prior to a period of motor training, ${ }^{12-14}$ has been found by previous studies to enhance the reacquisition of motor skills with the affected hand. These data confirm and extend these previous studies by demonstrating that ESS of the median nerve is effective to improve simple single joint movements as well as more complex reach-to-grasp movements performed with the affected hand after stroke.

Somatosensory input is essential for motor learning, ${ }^{24}$ and it has been suggested that an increase in the excitability of corticospinal projections to muscles of the paretic hand may facilitate functional recovery of dexterity after stroke. ${ }^{925}$ Corticospinal excitability can be increased in healthy subjects by periods of electrical peripheral nerve stimulation, ${ }^{910}$ transcranial direct current brain stimulation ${ }^{26}$ or a combination of peripheral nerve and transcranial brain stimulation. ${ }^{27}$ Stroke involving the primary motor cortex and/or the corticospinal tract reduces cortical excitability. ${ }^{32}{ }^{33}$ The degree of reduction in motor cortical excitability correlates with the amount of motor impairment of the affected hand after stroke. ${ }^{34}$ In stroke rehabilitation, specific training or repetitive exercise can increase corticospinal excitability and improve function of the paretic hand. ${ }^{31}{ }^{32}$ Physiotherapy involving repetitive practice of manual activities relevant in daily life is more effective than traditional rehabilitative approaches to improve impaired hand function ${ }^{33}$ and also causes an increase in cortical excitability of motor areas of the affected hemisphere after stroke. ${ }^{34}$

Repetitive peripheral magnetic or electrical stimulation may interfere with increased muscle tone caused by spasticity and thereby improves movement kinematics of the upper limb following stroke. ${ }^{35}$ Supra-threshold stimulation of peripheral motor or mixed sensory-motor nerves (or nerve roots) causes contraction of the targeted muscles. This generates proprioceptive input to the central nervous system via (1) activation of mechanoreceptors of the stimulated muscles during contraction and (2) direct activation of sensory-motor afferents. Suprathreshold stimulation of peripheral nerves significantly reduces spasticity of the muscles innervated by the stimulated nerve and thereby facilitates fine movements of the hand and fingers after stroke. ${ }^{35}$ Whether the effect of peripheral somatosensory stimulation develops on a spinal level or within the sensorymotor network of the brain is still under debate. None of our patients had relevant spasticity within the muscles of the affected upper limb. Consequently, possible mechanisms engaged in the behavioural improvement of motor function of the affected hand induced by ESS could include facilitation of sensorimotor integration in the relevant brain networks, which remained unaffected by stroke or in motor areas, which 

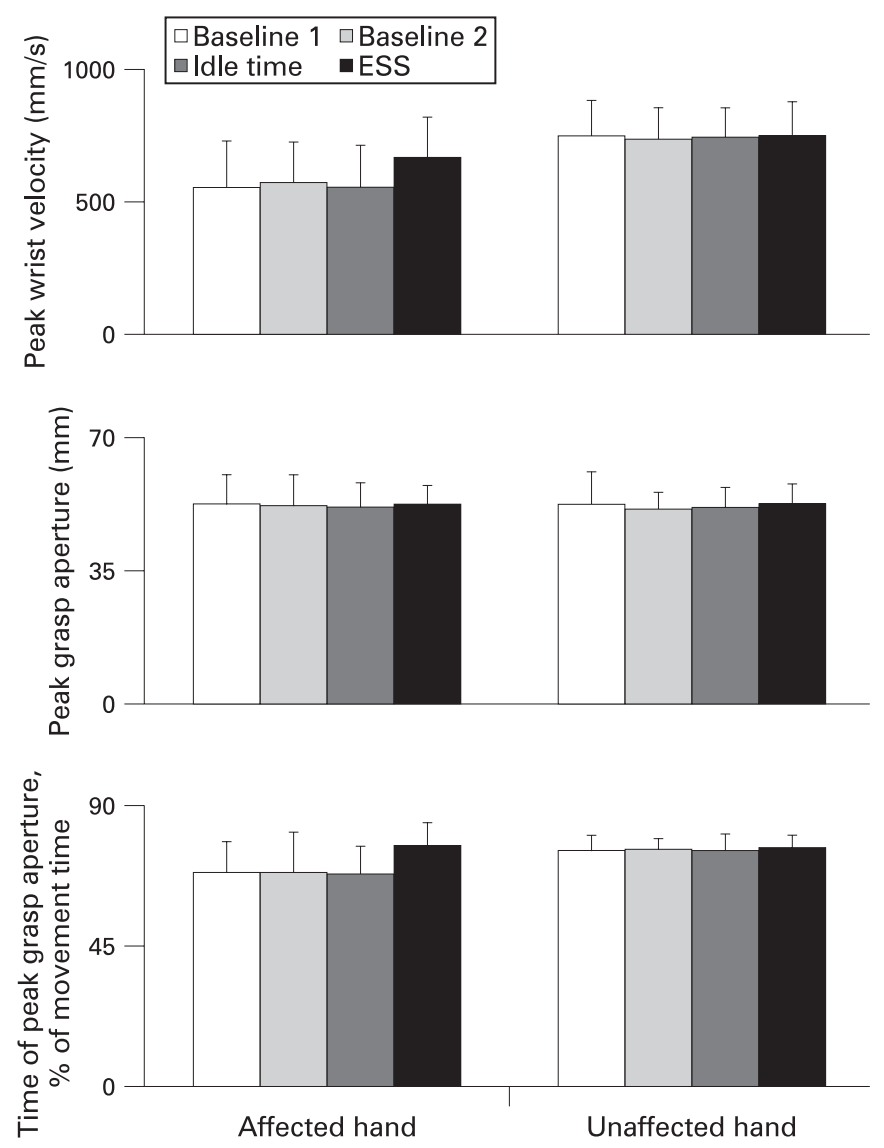

Figure 3 Mean values (+1SD) of peak wrist velocity, peak grasp aperture and time of peak grasp aperture as a percentage of movement time obtained from reach-to-grasp movements performed with the unaffected and affected hand prior to (baseline 1 and 2) and following a $2 \mathrm{~h}$ period of idle time or a $2 \mathrm{~h}$ period of electrical somatosensory stimulation. ESS, electrical somatosensory stimulation.

compensate for the functional deficit induced by the brain lesion. ${ }^{36}$

An alternative interpretation for the mechanism of action of ESS refers to interhemispheric competition models for sensory and/or motor processing. ${ }^{1267}$ The balance of cortical excitability between the motor areas of both hemispheres is changed after stroke with enhanced excitability and neural activity of motor areas within the unaffected hemisphere and abnormally increased interhemispheric, that is transcallosal, inhibition exerted upon the motor areas of the affected hemisphere. ${ }^{26737}$ Within this context, strategies to improve motor function of the affected hand after stroke may include (1) upregulation of excitability of motor areas within the stroke-affected hemisphere or (2) downregulation of excitability of motor areas within the unaffected hemisphere. ${ }^{7}$ ESS of the median nerve of the affected hand after stroke is regarded to increase cortical excitability and neural activity within cortical motor areas of the affected hemisphere and thereby has the potential to improve motor performance of the affected hand..$^{7-14}$

A recent study demonstrated that transient ischaemic cutaneous anaesthesia of the unaffected hand, but not the unaffected foot, resulted in a reduction of the transcallosal inhibitory drive from the motor cortex of the unaffected hemisphere towards the motor cortex of the affected hemisphere and at the same time improved the frequency of indexfinger tapping with the affected hand in chronic stroke. ${ }^{38}$ These data confirm these previous observations and provide, for the first time, a detailed kinematic analysis of the components of dextrous movements, which are most sensitive to ESS. Knowledge about the details underlying the beneficial effects of ESS on the performance of dextrous movements relevant in daily life after stroke may enrich the development novel behavioural concepts in rehabilitation. This appears most relevant, as it has been demonstrated that ESS in combination with motor training facilitates consolidation of the beneficial effects of rehabilitative treatments based on practice of motor tasks. ${ }^{12}$ However, we have not evaluated if ESS-induced improvement of movement kinematics also impacts on motor activities of the affected hand in daily life after stroke. In addition, we have not tested for how long the effects of ESS on hand motor function persist after stimulation has ceased. More research is needed to address these issues and investigate if the application of ESS alone or in combination with motor training generates carryover effects to manual activities of daily life after stroke.

Stroke is the leading cause for disability in Europe and the USA ${ }^{39}$ Recovery of motor deficits of the hand following stroke is incomplete in the majority of affected cases despite intensive rehabilitation..$^{40}$ Given these epidemiological facts, there is a socio-economical need to develop and implement innovative, neurobiological strategies in stroke rehabilitation. Despite a large heterogeneity of lesions and the possible mechanisms underlying recovery of function, these data taken together with previous studies strongly suggest that electrical somatosensory stimulation may be used to enhance hand motor function in subjects with chronic subcortical stroke. We provide kinematic evidence that ESS of the median nerve of the affected hand has the potential to improve movement kinematics of the affected hand in chronic stroke. In addition, these data strongly support the concept of interhemispheric competition and are hence of particular relevance for current efforts to implement ESS within novel concepts for stroke rehabilitation, as they supply a putative mechanism that can be targeted by specific therapeutic approaches. Future studies in larger samples of stroke survivors need to evaluate the adjuvant role of ESS implemented in conventional training concepts, for example a combined application of ESS with physiotherapy provided repetitively over several days or weeks, to improve impaired motor function of the hand in daily life after stroke.

Acknowledgements: This work is part of the first author's dissertation at the University of Cologne.

Funding: DAN was supported by an internal grant of the Köln Fortune Stiftung. Competing interests: None.

Ethics approval: Ethics approval was provided by the Ethics Committee of the University of Cologne.

Patient consent: Obtained.

\section{REFERENCES}

1. Kinsbourne M. Mechanisms of hemispheric interaction in man. In: Kinsbourne M, Smith WL, eds. Hemispheric disconnection and cerebral function. Springfield: Thomas, 1974;260-85.

2. Ferbert A, Priori A, Rothwell JC, et al. Interhemispheric inhibition of the human motor cortex. J Physiol 1992;453:525-46.

3. Gilio F, Rizzo V, Siebner HR, et al. Effects on the right motor hand-area excitability produced by low-frequency rTMS over human contralateral homologous cortex. J Physiol 2003;551:563-73.

4. Fink GR, Frackowiak R, Pietrzyk U, et al. Multiple nonprimary motor areas in the human cortex. J Neurophysiol 1997;77:2164-74.

5. Binkofski F, Buccino G, Stephan KM, et al. A parieto-premotor network for object manipulation: evidence from neuroimaging. Exp Brain Res 1999;128:210-13.

6. Liepert J, Hamzei F, Weiller C. Motor cortex disinhibition of the unaffected hemisphere after acute stroke. Muscle Nerve 2000;23:1761-3. 
7. Hummel FC, Cohen LG. Non-invasive brain stimulation: a new strategy to improve neurorehabilitation after stroke. Lancet Neurol 2006;5:708-12.

8. Kaelin-Lang A, Luft AR, Sawaki L, et al. Modulation of human cortico-motor excitability by somatosensory input. J Physiol 2002;540:623-33.

9. Ridding MC, Brouwer B, Miles TS, et al. Changes in muscle responses to stimulation of the motor cortex induced by peripheral nerve stimulation in human subjects. Exp Brain Res 2000;131:135-43.

10. Conforto $\mathbf{A B}$, Kaelin-Lang A, Cohen LG. Increase in hand muscle strength of stroke patients after somatosensory stimulation. Ann Neurol 2002;51:122-5.

11. Wu CW, Seo HJ, Cohen LG. Influence of electric somatosensory stimulation on paretic hand function in chronic stroke. Arch Phys Med Rehabil 2006;87:351-7.

12. Conforto $\mathbf{A B}$, Cohen LG, dos Santos RL, et al. Effects of somatosensory stimulation on motor function in chronic cortico-subcortical strokes. J Neurol 2007;254:333-9.

13. Peurala SH, Pitkänen K, Sivenius J, et al. Cutaneous electrical stimulation may enhance sensorimotor recovery in chronic stroke. Clin Rehabil 2002;16:709-16.

14. Sawaki L, Wu CW, Kaelin-Lang A, et al. Effects of somatosensory stimulation on use-dependent plasticity in chronic stroke. Stroke 2006;37:246-7.

15. Crovitz HF, Zener K. A group for assessing hand and eye dominance. Am J Psychol 1965;75:271-6.

16. Folstein MF, Folstein SE, McHugh PR. Mini-Mental State. A practical method for grading the cognitive state of patients for the clinician. J Psychiatr Res 1975;12:189-98

17. Schenkenberg T, Bradfort DC, Ajax ET. Line bisection and unilateral visual neglect in patients with neurological impairment. Neurology 1980;30:509-17.

18. O'Hare A, Gorzowska J, Elton R. Development of an instrument to measure manual praxis. Develop Med Child Neurol 1999:41:597-607.

19. Beck AT, Ward CH, Mendelson $\mathrm{M}$, et al. An inventory for measuring depression. Arch Gen Psychiatry 1961;4:561-71.

20. Lyle RC. A performance test for assessment of upper limb function in physical rehabilitation treatment and research. Intern J Rehab Res 1981;4:483-92.

21. Nowak DA, Grefkes C, Dafotakis M, et al. Dexterity is impaired at both hands following unilateral subcortical middle cerebral artery stroke. Eur J Neurosci 2007;25:3173-84.

22. Brott T, Adams HP Jr, Olinger CP, et al. Measurements of acute cerebral infarction: a clinical examination scale. Stroke 1989;20:864-70.

23. Bonita R, Beaglehole R. Modification of Rankin Scale: Recovery of motor function after stroke. Stroke 1988:19:1497-500.

24. Asanuma H. Functional role of sensory inputs to motor cortex. Prog Neurobiol 1981;16:241-62.

25. Talelli $\mathbf{P}$, Rothwell JC. Does brain stimulation after stroke has a future? Curr Opin Neurol 2006;19:543-50
26. Nitsche MA, Paulus W. Excitability changes induced in the human motor cortex by weak transcranial direct current stimulation. J Physiol 2000;527:633-9.

27. Stefan K, Kunesch E, Cohen LG, et al. Induction of plasticity in the human motor cortex by paired associative stimulation. Brain 2000;123:572-84.

28. Byrnes ML, Thickbroom GW, Phillips BA, et al. Physiological studies of the corticomotor projection to the hand after subcortical stroke. Clin Neurophysiol 1999;110:487-98.

29. Traversa R, Cicinelli P, Bassi A, et al. Mapping of motor cortical reorganization after stroke. A brain stimulation study with focal magnetic pulses. Stroke 1997:28:110-17.

30. Thickbroom GW, Byrnes ML, Archer SA, et al. Motor outcome after subcortical stroke: MEPs correlate with hand strength but not dexterity. Clin Neurophysiol 2002;113:2025-9.

31. Muellbacher W, Richards C, Ziemann U, et al. Improving hand function in chronic stroke. Arch Neurol 2002;59:1278-82.

32. Liepert J, Graef $\mathrm{S}$, Uhde I, et al. Training-induced changes of motor cortex representations in stroke patients. Acta Neurol Scand 2000;101:321-6.

33. Winstein CJ, Rose DK, Tan SM, et al. A randomized controlled comparison of upperextremity rehabilitation strategies in acute stroke: a pilot study of immediate and long-term outcomes. Arc Phys Med Rehabil 2004;85:620-8.

34. Jang SH, Kim YH, Cho SH, et al. Cortical reorganization induced by task-oriented training in chronic hemiplegic stroke patients. Neuroreport 2003;14:137-41.

35. Struppler A, Havel P, Müller-Barna P. Facilitation of skilled finger movements by repetitive peripheral magnetic stimulation (RPMS) - a new approach in central paresis. NeuroRehabilitation 2003:18:69-82.

36. Calautti C, Baron JC. Functional neuroimaging studies of motor recovery after stroke in adults: a review. Stroke 2003:34:1553-66.

37. Nowak DA, Grefkes C, Dafotakis M, et al. Effects of low frequency rTMS over contralesional motor cortex on movement kinematics and movement-related neural activation in subcortical stroke. Arch Neurol 2008;65:741-7.

38. Floel A, Hummel F, Duque J, et al. Influence of somatosensory input on interhemispheric interactions in patients with stroke. Neurorehabil Neural Repair. In press.

39. Kolominsky-Rabas PL, Weber M, Gefeller 0, et al. Epidemiology of ischemic stroke subtypes according to the TOAST criteria: incidence, recurrence, and long-term survival in ischemic stroke subtypes: a population-based study. Stroke 2001;32:2735-40

40. Kwakkel G, Kollen BJ, Wagenaar RC. Long-term effects of intensity of upper and lower limb training following stroke: a randomised trial. J Neurol Neurosurg Psychiatry 2002; 72:473-9.

41. Nakayama H, Jorgensen HS, Raaschou HO, et al. Recovery of upper extremity function in stroke subjects: the Copenhagen Stroke Study. Arch Phys Med Rehabil 1994; 75:394-8. 